\title{
Immunization status and child survival in rural Ghana
}

Philomena Nyarko

Brian Wells Pence

Population Council

Cornelius Debpuur

Follow this and additional works at: https://knowledgecommons.popcouncil.org/departments_sbsr-pgy

Part of the Demography, Population, and Ecology Commons, Family, Life Course, and Society Commons, International Public Health Commons, and the Maternal and Child Health Commons How does access to this work benefit you? Let us know!

\section{Recommended Citation}

Nyarko, Philomena, Brian Wells Pence, and Cornelius Debpuur. 2001. "Immunization status and child survival in rural Ghana," Policy Research Division Working Paper no. 147. New York: Population Council. 


\section{Immunization Status and Child Survival in Rural Ghana}

Philomena Nyarko

Brian Pence

Cornelius Debpuur

2001 No. 147 


\title{
Immunization Status and Child Survival in Rural Ghana
}

\author{
Philomena Nyarko \\ Brian Pence \\ Cornelius Debpuur
}

Philomena Nyarko and Cornelius Debpuur are Postdoctoral Research Fellows at the Navrongo Health Research Centre in Ghana. Brian Pence is Research Coordinator in the Policy Research Division, Population Council, New York.

The authors express their gratitude to Peter Wontuo and to the data collection and management team of the Navrongo Demographic Surveillance System. They also thank Fred N. Binka, James F. Phillips, and Peter Smith for helpful comments on earlier drafts of this paper. 


\begin{abstract}
For three decades, the Expanded Programme on Immunization (EPI) has been promoted as one of the key child health interventions in developing countries. Vaccines for six childhood diseases (diphtheria, measles, pertussis, poliomyelitis, tetanus, and tuberculosis) have been shown to be efficacious in preventing disease-specific morbidity and mortality, yet not all commentators are convinced that the EPI reduces all-cause child mortality. Numerous studies have found that measles vaccination programs substantially reduce all-cause child mortality, but recent findings from Guinea-Bissau suggest that diphtheria, pertussis, and tetanus (DPT) vaccine may increase all-cause child mortality.

The present study uses five years of data from the Navrongo Demographic Surveillance System, a longitudinal population registration system in northern Ghana, to examine all-cause mortality among vaccinated and unvaccinated children under 5 years of age. The data indicate that coverage by one Bacillus Calmette-Guérin (BCG) shot, three sets of polio drops, and three DPT shots reduces mortality between ages 4 and 8 months by nearly 90 percent. Complete coverage by all EPI antigens reduces mortality between ages 9 and 59 months by 70 percent. BCG, polio, and DPT vaccines without measles vaccination reduce mortality by 40 percent. The independent reduction in mortality associated with measles vaccination is 50 percent. Our data add to a growing body of evidence that suggests that measles vaccination programs reduce all-cause mortality substantially beyond the proportion of deaths caused by measles. These results indicate a need for further research in developing countries on the all-cause mortality impact of these vaccines, in particular DPT vaccine.
\end{abstract}

This material may not be reproduced without written permission from the authors. 
Despite recent improvements in child survival in Ghana, mortality levels are still very high. The estimated national infant mortality rate is 57 per 1,000 live births while under-5 mortality is 108 per 1,000 live births (Ghana Statistical Service and Macro International 1999). In rural settings where health services are not accessible to a large proportion of the population, the situation is even worse. In Kassena-Nankana District, a typical rural Guinea savannah area, infant and under-5 mortality rates for 1999 are 90.0 and 151.9 per 1,000 live births, respectively. These levels are exceptionally high as compared to estimated national figures. Furthermore, more than 60 percent of children in the district die of preventable diseases (Binka et al. 1995).

In response to the worldwide call to improve child survival, the Expanded Programme on Immunization (EPI) advocated by UNICEF was wholly embraced by Ghana in the early 1980s. As in most developing countries, immunization against the six immunizable childhood diseases (i.e., diphtheria, measles, pertussis, poliomyelitis, tetanus, and tuberculosis) has been instituted as part of Ghana's primary health care program. Access to the antigens is mainly through outreach programs, particularly in remote areas, and through routine child clinic sessions at health care facilities. While the EPI in Ghana in the early 1980s was described as a great success, falling coverage rates characterized the period 1986-91 (UNICEF 1993). In the last decade, however, Ghana has experienced a modest upturn in full vaccination rates, from 55 percent in 1993 to 62 percent in 1998 for all one-year-olds (Ghana Statistical Service and Macro International 1999). Despite this improvement, the worldwide target of 90 percent coverage by the year 2000 is far from being attained.

The lack of reliable data on EPI-targeted diseases as causes of death makes it difficult to assess the magnitude of mortality reductions due to immunization uptake. It has been argued that reductions in disease-specific mortality will not necessarily translate into improvements in child survival in situations where children are at high risk of death from other causes. This argument holds that those "saved" by immunization may be weaker, on average, than those who would have survived without immunization, and therefore more likely to die of other causes (Koenig, Fauveau, and Wojtyniak 1991; Mosley and Chen 1984; Kasongo Project Team 1981). Others have argued against this 
view, claiming that immunization prevents not only death but also illness, thereby promoting the overall health of the child and reducing mortality by more than the share of deaths directly attributable to the targeted diseases (Kristensen, Aaby, and Jensen 2000; Aaby 1995; Koenig et al. 1991). Further, immunization drives could affect mortality through behavioral as well as biomedical pathways. Health workers generally use designated national immunization days (NIDs) to measure and weigh children and provide a wide range of health-related information. NIDs serve as a contact point with the official health care system for mothers, especially in rural areas, who might otherwise rarely interact with the system.

However, logistical difficulties, particularly in settings such as rural northern Ghana, may limit an immunization program's potential for impact. In most rural areas, the schedules for EPI outreach may not correspond to the exact time at which a child is due for a particular antigen. For maximum protection against the six childhood killer diseases, it is recommended that a child receive one dose of Bacillus Calmette-Guérin (BCG) at birth; three doses of diphtheria, pertussis, and tetanus (DPT) vaccine and polio drops at ages 6,10, and 14 weeks; and the measles vaccine at age 9 months. Outreach programs are usually planned to correspond to days of local activity (such as market days, nonfarming/nonfishing days, and so forth) and at reasonable intervals to ensure adequate response to the call to send children to outreach points. Complete uptake may, therefore, not necessarily result in improvements in child survival because vaccinations may be mistimed. In other situations, mothers may fail to return for later vaccines. This is particularly true for the measles vaccine, which should be given nearly six months after completion of the rest of the series. Thus, the full benefit of the immunization routine for the child may not be achieved.

In addition, vaccines may lose their sensitivity during transportation between a health institution and an outreach point because of unsatisfactory storage facilities. Most vaccines need to be stored at low temperatures to maintain their potency. In cases where the cold chain is broken due to unavailability of refrigeration facilities, the antigen may have lost its effectiveness by the time it is administered to a child. This problem of transporting vaccines under unsatisfactory conditions is often encountered in rural areas. 
In Kassena-Nankana District, however, efforts are made to maintain the cold chain by providing vaccines to nurses just before they begin their outreach duties. Nevertheless, considering that the climate in the district is very hot and temperatures can reach $40^{\circ} \mathrm{C}$, even an hour's drive to an outreach point can break the cold chain.

The aim of this paper is to examine the influence of immunization coverage on all-cause child mortality in Kassena-Nankana District of northern Ghana. Five years of longitudinal data on child survival and immunization status permit a detailed analysis of the mortality experiences of children who have received none, some, or all of the EPIrecommended immunizations.

\section{SOURCE OF DATA AND SAMPLE SELECTIVITY}

The data used for the analysis are based on the Navrongo Demographic Surveillance System (NDSS). The NDSS is a longitudinal population registration system established in Kassena-Nankana District in 1993 to support research into rural health problems and to provide a means for testing various health intervention strategies. Surveillance activities began with a baseline census in July 1993. Since then, demographic events have been continuously updated through visits to village compounds at 90-day intervals. Data are collected on births, deaths, in- and out-migration, marriages, and pregnancies. Also included in the database is basic demographic information such as sex, dates of events, and relationships of household members.

In addition, data on vaccination status have been collected annually beginning in 1996 for children less than 2 years of age at the time of interview. The interviewer records dates of vaccination only if the mother has a health card or some other written record of the date and the vaccination given. This means that some of the children classified as not vaccinated may in fact have received vaccinations but lost their health cards by the time of the survey. Between 50 and 60 percent of children had a health card or other written record in each of the four surveys from 1996 to 1999. The data used in this paper include children who were born in the study area between 1 October 1994 and 31 December 1999 and for whom information is available in at least one of the vaccination surveys. Children who were born elsewhere and migrated into the study area were excluded 
even if information on them was available in one of the vaccination surveys. Because of the high level of out-migration in the district, some children are likely to be missed in these vaccination surveys in early childhood; even if they return they may then be too old to qualify for inclusion. In addition, because the annual vaccination survey collects information only on living children, children who were born and then died between successive surveys are not included in the vaccination database.

Table 1 compares background characteristics of the children in the main NDSS database with those included in the vaccination surveillance database in order to provide an idea of the selectivity of the sample used for the analysis. The cells indicated in the table refer to the Community Health and Family Planning Project (CHFP) experiment cells representing alternative approaches to primary health care delivery in geographically contiguous areas (Binka, Nazzar, and Phillips 1995). Each cell corresponds to the catchment area of a health center in Kassena-Nankana District. The "Zurugelu" intervention in Cell 1 seeks to increase community involvement in health decisions by involving traditional village structures (chiefs, elders, and soothsayers) and volunteers in planning and delivering health activities and services and introducing project messages into traditional community meetings. The strategy for Cell 2 involves reorientation and relocation of community health nurses from the health centers to community health centers in the villages, where they both live and work. Cell 3 combines the Cell 1 and Cell 2 strategies. Cell 4 is the comparison area, in which both the Zurugelu and relocated nurses are absent, and only the normal Ministry of Health approach to health delivery operates (i.e., a health center with outreach to communities). Cell 5, the only urban section of the district, is not included in the CHFP. However, demographic surveillance and vaccination data are collected in this area.

From Table 1, it is evident that the sample used for the analysis is comparable to the main child database on sex, cell of residence, and number of compound residents. The disparity in the distribution of age at first observation is due to the fact that the analysis is restricted to those born in the study area. Maternal and paternal characteristics are unknown for a smaller proportion of those included in the analysis compared to those not included, which is also a result of the fact that only children followed from birth are included in the analysis. 
The bias in the selected sample with respect to the survival status of the child is also to be expected because the immunization schedule is administered only once a year to surviving children. Children who are born and die between two surveys (i.e., many of those who die in the neonatal and early post-neonatal periods, when a large fraction of under-5 mortality occurs) do not appear in the vaccination database. This analysis is therefore biased toward surviving children between the ages of 0 and 9 months. The table indicates that survival of children from 9 to 59 months is comparable between those included and those excluded, however. This bias therefore does not affect analysis restricted to the 9-59-month age group.

Table 1 indicates that mother's information is missing for 0.3 percent of the children. These children were subsequently excluded from the study, bringing the final sample to 17,701 . The fathers of approximately 12 percent of the children are unknown. For this reason, paternal education and residence are not included as explanatory variables in the analysis.

\section{METhOdS OF ANALYSIS}

A central question in planning this analysis concerns the definition of vaccination coverage. An appealing approach would be to simply create one indicator variable for each of the eight EPI antigens (BCG; polio 1, 2, and 3; DPT 1, 2, and 3; and measles) to indicate whether a child had received that antigen at a given age. Regression techniques could then be used to assess the independent contribution of each of the antigens to survival while holding constant the other seven, and to assess the combined mortality impact of the full EPI package. However, these eight variables are extremely highly correlated for obvious reasons: polio 1 and DPT 1 are given at the same time, and the

mother who has taken her child to the clinic to receive the first set of shots is more likely to take the child back to receive the second set. Such high correlations between explanatory variables make it impractical to consider each antigen separately.

Research from other studies has demonstrated substantial reductions in mortality associated with measles immunization programs (Aaby 1995; Koenig, Fauveau, and Wojtyniak 1991). We therefore considered it important to assess the independent contribution of measles immunization to survival in this population. Because BCG, polio, and 
Table 1 Distribution of children included and not included in the analysis by background characteristics

\begin{tabular}{|c|c|c|c|}
\hline \multirow[b]{2}{*}{$\begin{array}{l}\text { Background } \\
\text { characteristic }\end{array}$} & \multicolumn{3}{|c|}{ Percent distribution of children } \\
\hline & $\begin{array}{l}\text { Children included } \\
\text { in analysis }\end{array}$ & $\begin{array}{l}\text { Children not included } \\
\text { in analysis }\end{array}$ & $\begin{array}{l}\text { All children } \\
\text { in study area }\end{array}$ \\
\hline \multicolumn{4}{|c|}{$\begin{array}{l}\text { Survival status of child } \\
\text { All ages (0-59 months) }\end{array}$} \\
\hline Alive & 91.2 & 77.0 & 87.5 \\
\hline Dead & 8.8 & 23.0 & 12.5 \\
\hline \multicolumn{4}{|l|}{ 9-59 months } \\
\hline Alive & 93.9 & 94.0 & 93.9 \\
\hline Dead & 6.1 & 6.0 & 6.1 \\
\hline \multicolumn{4}{|l|}{ Sex of child } \\
\hline Male & 49.9 & 49.4 & 49.7 \\
\hline Female & 50.1 & 50.6 & 50.3 \\
\hline \multicolumn{4}{|l|}{ Cell location } \\
\hline Cell 1 & 15.0 & 13.6 & 14.7 \\
\hline Cell 2 & 14.7 & 13.6 & 14.4 \\
\hline Cell 3 & 32.6 & 29.2 & 31.7 \\
\hline Cell 4 & 32.5 & 31.7 & 32.3 \\
\hline Cell 5 & 5.2 & 12.0 & 7.0 \\
\hline \multicolumn{4}{|c|}{$\begin{array}{l}\text { Mother's age at birth } \\
\text { of child (years) }\end{array}$} \\
\hline $15-19$ & 11.2 & 11.6 & 11.3 \\
\hline $20-24$ & 21.9 & 23.6 & 22.4 \\
\hline $25-29$ & 22.5 & 20.8 & 22.0 \\
\hline $30-34$ & 19.4 & 16.6 & 18.7 \\
\hline $35-39$ & 15.6 & 11.1 & 14.4 \\
\hline $40+$ & 9.1 & 6.5 & 8.4 \\
\hline Missing & 0.3 & 9.8 & 2.8 \\
\hline \multicolumn{4}{|c|}{ Mother's education } \\
\hline None & 83.7 & 71.6 & 80.5 \\
\hline Some & 16.0 & 18.6 & 16.7 \\
\hline Missing & 0.3 & 9.8 & 2.8 \\
\hline
\end{tabular}




\begin{tabular}{|c|c|c|c|}
\hline \multirow[b]{2}{*}{$\begin{array}{l}\text { Background } \\
\text { characteristic }\end{array}$} & \multicolumn{3}{|c|}{ Percent distribution of children } \\
\hline & $\begin{array}{l}\text { Children included } \\
\text { in analysis }\end{array}$ & $\begin{array}{c}\text { Children not included } \\
\text { in analysis }\end{array}$ & $\begin{array}{l}\text { All children } \\
\text { in study area }\end{array}$ \\
\hline \multicolumn{4}{|l|}{ Mother's residence } \\
\hline Always resident & 87.1 & 77.1 & 84.5 \\
\hline Sometimes resident & 6.5 & 6.5 & 6.5 \\
\hline Never resident & 6.1 & 6.6 & 6.2 \\
\hline Missing & 0.3 & 9.8 & 2.8 \\
\hline \multicolumn{4}{|l|}{ Father's education } \\
\hline None & 70.4 & 50.0 & 65.1 \\
\hline Some & 17.9 & 15.8 & 17.3 \\
\hline Missing & 11.7 & 34.2 & 17.6 \\
\hline \multicolumn{4}{|l|}{ Father's residence } \\
\hline Always resident & 63.8 & 45.4 & 59.0 \\
\hline Sometimes resident & 14.5 & 7.3 & 12.6 \\
\hline Never resident & 10.0 & 13.0 & 10.8 \\
\hline Missing & 11.7 & 34.2 & 17.6 \\
\hline \multicolumn{4}{|l|}{ Mean compound members } \\
\hline $2-8$ & 22.2 & 25.0 & 23.0 \\
\hline $9-13$ & 23.7 & 25.0 & 24.0 \\
\hline $14-22$ & 28.3 & 27.7 & 28.1 \\
\hline $23+$ & 25.8 & 22.3 & 24.9 \\
\hline \multicolumn{4}{|l|}{$\begin{array}{l}\text { Age at first observation } \\
\text { (months) }\end{array}$} \\
\hline 0 & 100.0 & 47.1 & 86.2 \\
\hline $1-11$ & 0.0 & 26.1 & 6.8 \\
\hline $12-23$ & 0.0 & 13.7 & 3.6 \\
\hline $24-35$ & 0.0 & 8.0 & 2.1 \\
\hline $36-47$ & 0.0 & 3.5 & 0.9 \\
\hline $48-59$ & 0.0 & 1.5 & 0.4 \\
\hline Total number of children & 17,753 & 6,300 & 24,053 \\
\hline
\end{tabular}

${ }^{a}$ Mean number of compound members during observation of child.

${ }^{b}$ Age of child at first observation (beginning of study, birth, or in-migration). 
Figure 1 Vaccination coverage categories

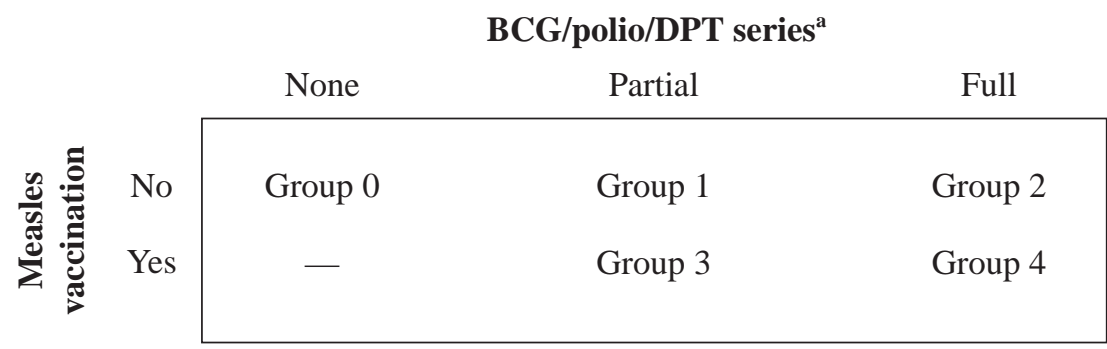

${ }^{a}$ Complete series consists of one BCG shot, three sets of polio drops, and three DPT shots.

DPT coverage are so highly correlated, we decided to consider them as a single package. Vaccination coverage is therefore defined first by whether the child has received no, partial, or full BCG/polio/DPT coverage, and second by whether the child has received the measles vaccine. This typology is illustrated in Figure 1. Only 14 children, representing 0.05 percent of the total person-time of observation, received the measles vaccine but none of the BCG/polio/DPT series. Since these were too few cases to form a separate category, these children were included in Group 0 until the time of their measles vaccination and then censored.

Kaplan-Meier survival functions and mortality rates (ratio of number of deaths to person-years of observation) for different age groups are used to examine differences in childhood mortality between the five categories of vaccination coverage described in Figure 1. Confidence intervals for rate ratios are calculated following Kelsey and colleagues (1996). Specifically, the variance of the $\log$ rate ratio is estimated as $\left(1 / d_{0}+1 / d_{1}\right)$, where $d_{0}$ and $\mathrm{d}_{1}$ refer to the number of events (deaths) in the two groups being compared.

A discrete-time hazards regression model is then used to estimate the effect of vaccination coverage on survival while controlling for potential confounding variables. In a hazards model, the risk of death is modeled as a function of time (in this case, age of the child) and other characteristics. The model accounts for censored survival times and allows individual characteristics to change over time. In this analysis, a censored child is one who survives until the end of observation or one who does not experience the 
event of death before being lost to follow-up, as in the case of out-migrant children. Uncensored children, on the other hand, are those who experience the event of death at the specified time.

The data for a discrete-time model are first structured as a series of Bernoulli trials, one for each discrete month; therefore, the covariates for a given child can assume different values from one month to the next. Thus a separate record is created for each unit of time for which the child is known to be at risk of death. A child who survives the first 5 years of life, for example, will have 60 records, while the child who dies at age 5 months will have 5 records. For each person-month, the dependent variable (survival status) is coded 1 if the child died during that month and 0 if the child survived. The discrete-time model can thus be fitted using any model for binary response data. Using the logit link, the probability of death $\mathrm{h}_{i t}$ for child $i$ at time $t$ is given by:

$$
h_{i t}=\frac{\exp ^{\left(\alpha_{t}+x_{i t}^{\prime} \beta\right)}}{1+\exp ^{\left(\alpha_{t}+x_{i t}^{\prime} \beta\right)}}
$$

where $\alpha_{t}$ is a function of time, $x_{i t}^{\prime}$ is a vector of covariates, and $\beta$ is a vector of parameters to be estimated.

The relationship of the outcome variable with time, $\alpha_{t}$, can be modeled in several ways. The simplest approach is to assume a constant relationship over time, for example, $\alpha_{t}=\alpha$. Other choices include a linear function of time, $\alpha_{t}=\alpha_{0}+\alpha_{1}$ t; a quadratic function, $\alpha_{t}=\alpha_{0}+\alpha_{1} t+\alpha_{2} t^{2}$; or a log-linear relationship, $\alpha_{t}=\alpha_{0}+\alpha_{1} \log (t)$. In this case, separate models were estimated for children aged 4-8 months and 9-59 months. In each model, exploratory analyses indicated that the linear function of age was the most appropriate, as it yielded a better fit than the logarithmic transformation of age and the addition of a quadratic term did not contribute significantly to the fit of the model.

Other explanatory variables considered for inclusion in the model are the child's sex and year of birth; the mother's age, education, and residential status; number of residents in the compound; cell location of the child; and distance to the nearest health facility and to Navrongo Town (the only urban center in the district). The mother's age at birth of the child, the year of birth of the child, and the number of compound residents 
are categorized, while sex of the child and maternal education and residence are represented by indicator variables. Logarithms were taken of the distance variables to normalize their highly skewed distributions.

Models were first specified using all potential explanatory variables. Variables with coefficients not significantly different from 0 at the 95 percent confidence level were removed one at a time, but were replaced if their removal caused any of the statistically significant coefficients to change by 10 percent or more. Certain variables considered to be of programmatic importance (such as the experimental cell of residence) were retained regardless of their level of statistical significance. To aid in the interpretation of the regression analysis, coefficients are exponentiated and presented as odds ratios.

\section{RESULTS}

\section{Immunization uptake and timing in the first year of life}

Table 2 shows the percentage of children immunized, the percentage receiving each vaccination at the recommended age, and the median age at vaccination among children who survived to the age of 12 months. If immunization does indeed reduce mortality, this table will overestimate actual coverage rates achieved, as there will be a higher proportion of immunized children among those who survive to age 12 months than among those who survive to the recommended age of immunization but die before age 12 months. As expected, vaccination rates are higher for vaccines received earlier in life, such as BCG, polio 1, and DPT 1. Although the uptake of measles vaccination is quite low, it appears to have the most strictly followed schedule. The last two columns of Table 2 indicate that a majority of children in the study population receive BCG, polio, and DPT vaccinations at a later age than is recommended (often a month or more later).

\section{Childhood mortality rates}

Figure 2 illustrates the differences in mortality risks during childhood between the five vaccination status categories. Figure 2 a compares the monthly mortality risk for months 4-8 (expressed as the number of deaths per 1,000 population at risk each month) for vaccination status Groups 0,1 , and 2 (those with no, partial, or full BCG/polio/DPT 
coverage, respectively, and no measles coverage). Children under 4 months of age are excluded because they will not have had time to complete the polio and DPT series, and Groups 3 and 4 are not considered because there are too few children immunized against measles prior to age 9 months to make comparison of mortality risks meaningful. Those who were vaccinated against measles prior to age 9 months were censored at that time for the purposes of this graph. Figures $2 b$ and $2 c$ compare monthly mortality risks for all five vaccination status groups for ages 9-23 and 24-59 months, respectively. The low numbers of deaths at later ages makes the month-by-month mortality risks somewhat erratic and difficult to compare. For ease of interpretation, therefore, Figure $2 b$ presents average monthly mortality risks for three-month age groups (9-11, 12-14, and so forth), and Figure 2c shows average monthly risks for six-month age groups (24-29, 30-35, and so forth).

It is apparent from Figures $2 a$ and $2 b$ that children who have received no immunizations are at substantially higher risk of death through approximately the first year of life than those who have some vaccination coverage, whether complete or incomplete. Those who have received some or all of the BCG/polio/DPT series (Groups 1 and 2)

Table 2 Immunization rates by age 12 months

\begin{tabular}{lccc}
\hline & $\begin{array}{c}\text { Percentage of } \\
\text { children immunized } \\
\text { by age 12 months } \\
\text { Vaccination type }\end{array}$ & $\begin{array}{c}\text { Percentage } \\
\text { of immunized } \\
\text { children who received } \\
\text { timely vaccinations }\end{array}$ & $\begin{array}{c}\text { Median age at } \\
\text { vaccination } \\
\text { (months) }\end{array}$ \\
\hline BCG & 71.7 & $36.3(9,443)$ & 1.6 \\
Polio 1 & 73.6 & $42.6(9,690)$ & 2.2 \\
Polio 2 & 65.6 & $27.3(8,631)$ & 3.9 \\
Polio 3 & 53.0 & $19.0(6,973)$ & 5.2 \\
DPT 1 & 72.6 & $36.5(9,553)$ & 2.4 \\
DPT 2 & 65.5 & $24.2(8,628)$ & 3.9 \\
DPT 3 & 56.3 & $16.5(7,412)$ & 5.5 \\
Measles & 45.1 & $75.1 \quad(5,941)$ & 9.1 \\
\hline
\end{tabular}

${ }^{a}$ Excludes children born in 1999.

${ }^{\mathrm{b}} \mathrm{N}$ is shown in parentheses. 
Figure 2 Monthly risk of death per 1,000 children, by age and vaccination status

a Ages 4-8 months

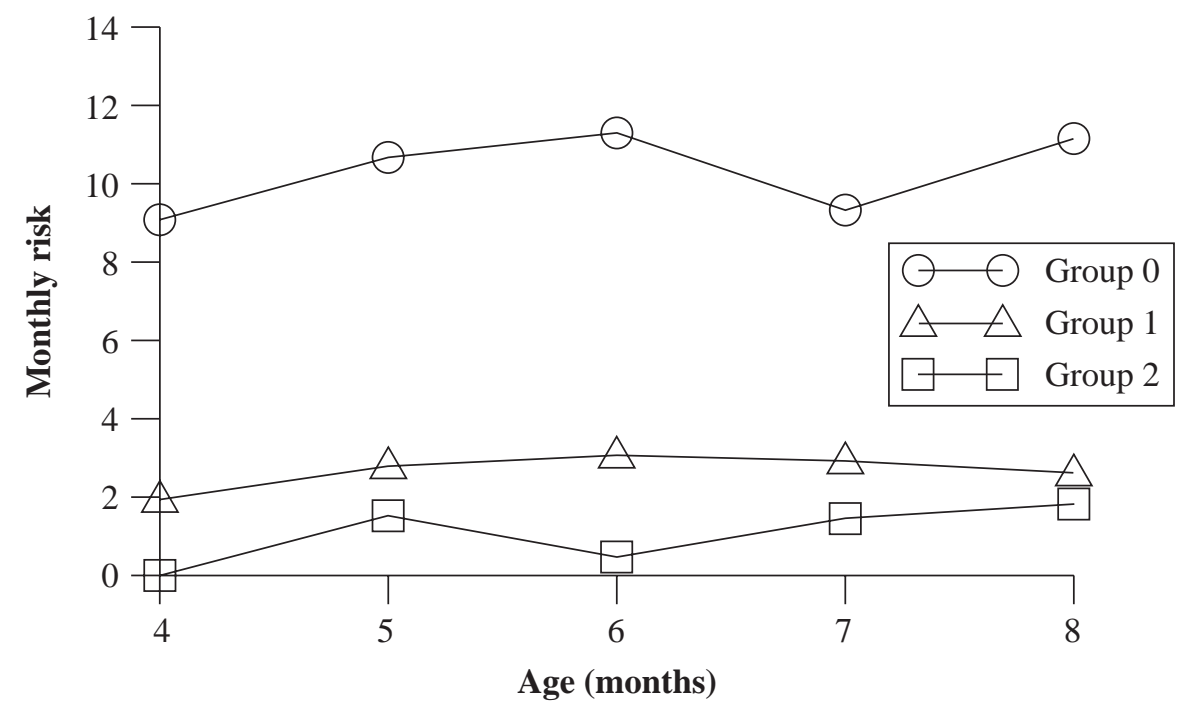

b Ages 9-23 months

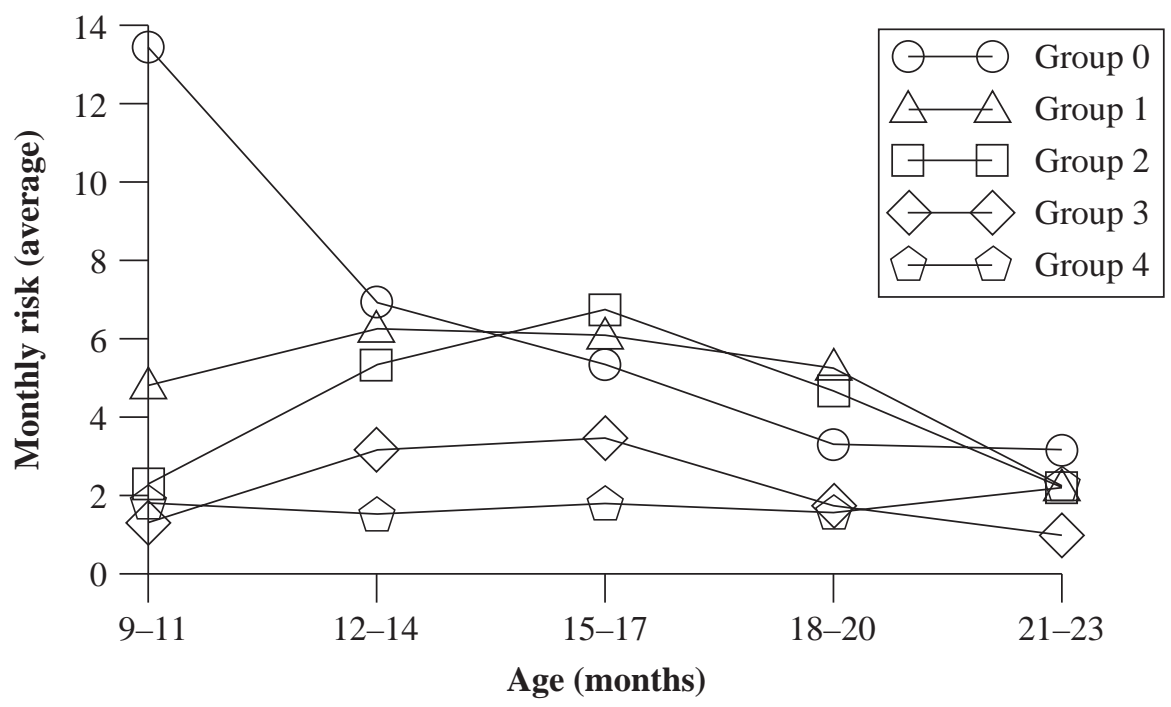


Figure 2 continued

c Ages 24-59 months

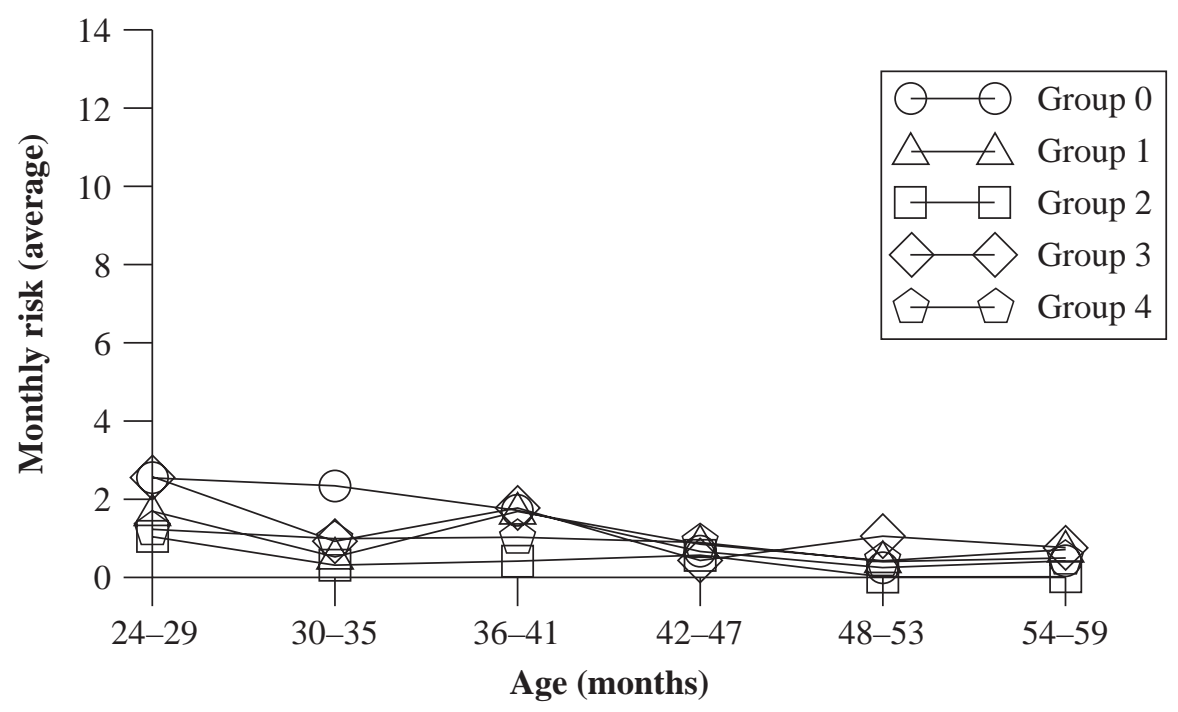

Note: Group $0=$ No immunizations; Group 1 = Partial BCG/polio/DPT coverage, no measles vaccine; Group 2 = Full BCG/polio/DPT coverage, no measles vaccine; Group 3 = Partial BCG/ polio/DPT coverage, measles vaccine; Group 4 = All immunizations (full BCG/polio/DPT coverage, measles vaccine).

face mortality risks approximately one-fourth to one-tenth those of the unvaccinated group (Group 0) in months 4-8 (Figure 2a) as well as in the 9-11-month age group (Figure 2b). During the second year of life (Figure 2b), little difference is evident between unvaccinated children and those who have received some or all of the BCG/polio/ DPT series without the measles vaccine. Those who have received the measles vaccine (Groups 3 and 4), whether or not they have completed the BCG/polio/DPT series, face mortality risks approximately half as high as unvaccinated children and children in Groups 1 and 2 during the same period. In the third year of life (months 24-29 and 30-35), mortality is lower in most of the vaccinated groups relative to the unvaccinated, although the differences are generally small. In the fourth and fifth years of life, when mortality is low overall, there is little difference between the five groups. 
Figure 3 Kaplan-Meier survival functions by vaccination status

a Ages 4-8 months

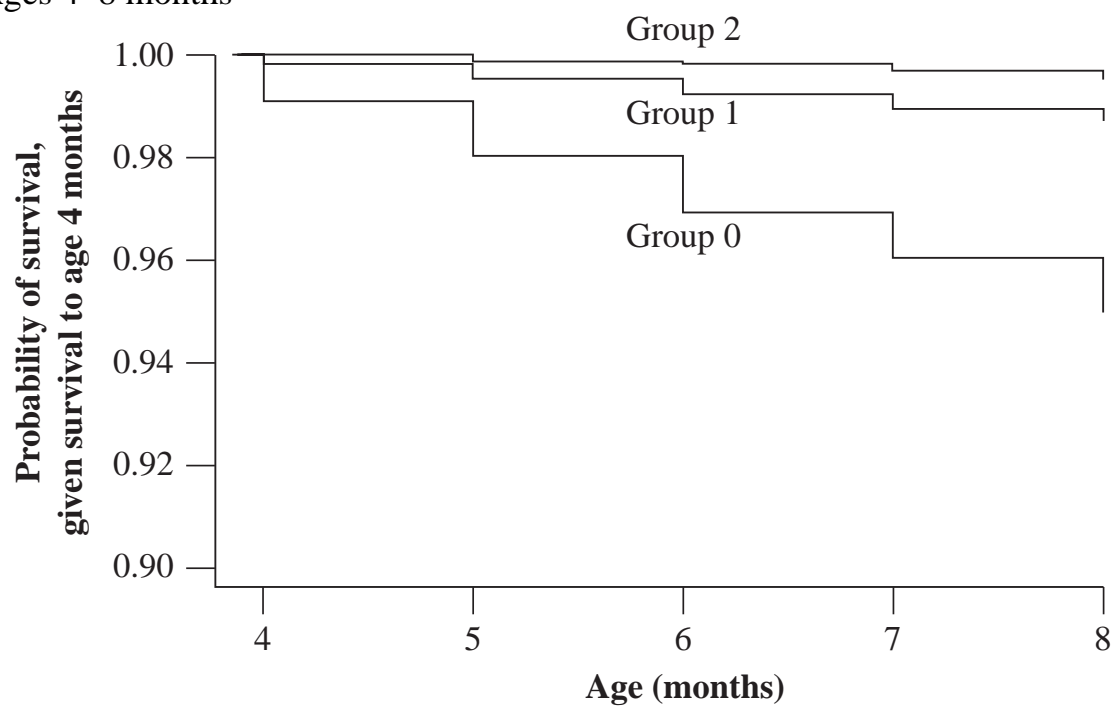

b Ages 9-59 months

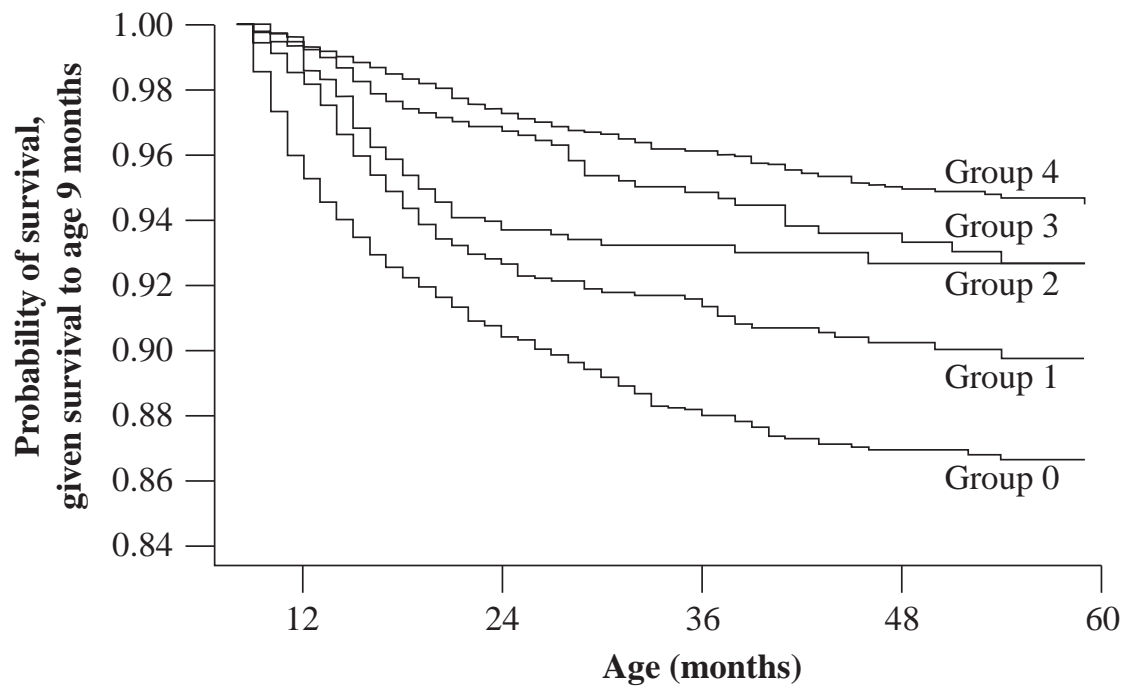

Note: Group $0=$ No immunizations; Group $1=$ Partial BCG/polio/DPT coverage, no measles vaccine; Group 2 = Full BCG/polio/DPT coverage, no measles vaccine; Group $3=$ Partial BCG/ polio/DPT coverage, measles vaccine; Group $4=$ All immunizations (full BCG/polio/DPT coverage, measles vaccine). 
Even though the mortality differentials in later childhood are small, the differences in infancy and early childhood lead to substantially higher cumulative under-5 survival for vaccinated children than for unvaccinated children. Figure 3 shows KaplanMeier survival functions by vaccination status. Figure 3a examines Groups 0,1 , and 2 over the 4-8-month age range, while Figure $3 b$ compares all five groups from 9 to 59 months. There is a clear trend linking more complete vaccination coverage with increased probability of survival until the fifth birthday.

Table 3 presents rate ratios summarizing the total gain in survival in late infancy and childhood associated with vaccination status. Mortality rates for each group over each age range were calculated as the number of deaths divided by person-years of observation; within each age range, the rates for each of Groups 1-4 were then divided by the rate for Group 0 to obtain these ratios. Ninety-five percent confidence intervals for the rate ratios are shown in parentheses.

The calculated confidence intervals indicate that almost all rate ratios are significantly lower than 1.00 at the 95 percent confidence level. The only exceptions are rate ratios comparing Groups 1 and 2 to Group 0 (the unvaccinated children) at ages 12-23 months and comparing Group 3 to Group 0 at ages 24-59 months, for which the confidence intervals include 1.

Over the age range 9-59 months, the total reduction in mortality associated with immunization ranges from 25 percent for children with partial BCG/polio/DPT coverage and no measles vaccination to 70 percent for those with the full complement of UNICEF-recommended vaccinations. The incremental reduction in mortality over this age range associated with measles vaccination alone is around 50 percent, as can be seen by comparing groups with comparable BCG/polio/DPT status but different measles vaccination status. The rate ratio (RR) comparing Group 3 to Group 1 for children ages 9-59 months is $0.54(95 \% \mathrm{CI}=[0.39,0.73])$, and the RR comparing Group 4 to Group 2 is $0.50(95 \% \mathrm{CI}=[0.40,0.64])$. It is counter-intuitive that at $24-59$ months, those who received the measles vaccine experienced higher mortality than those with comparable $\mathrm{BCG} /$ polio/DPT coverage but no measles vaccine. However, mortality rates in this age range have large standard errors due to the small number of deaths, and statistical tests do not allow us to conclude that mortality differs significantly between children vaccinated 


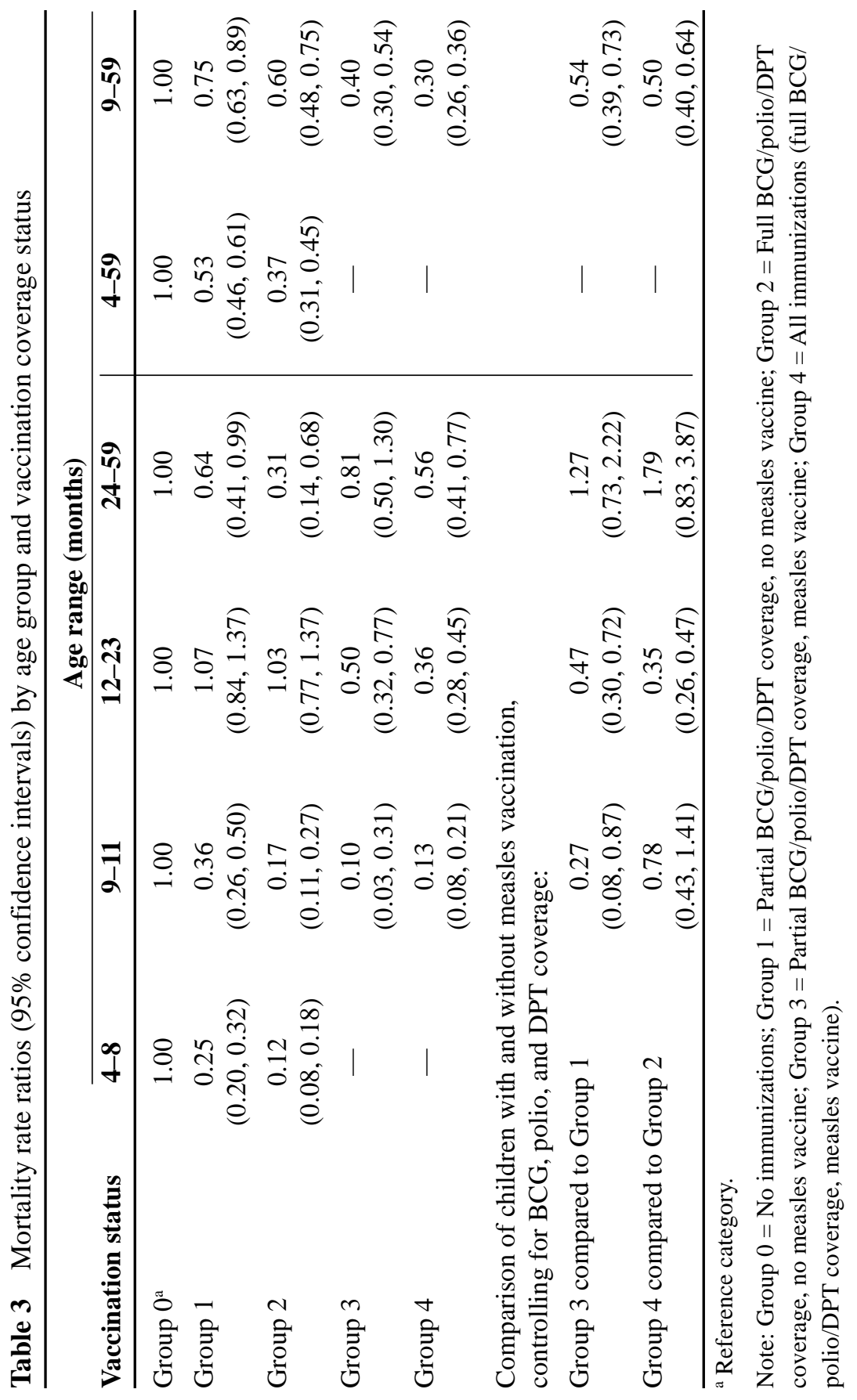


Table 4 Discrete-time hazards regression model for examining the effect of the degree of immunization uptake and mortality in the 4-8-month age group

\begin{tabular}{|c|c|c|c|c|c|}
\hline Variable & Coefficient & Standard error & P-value & Odds ratio & $95 \% \mathrm{CI}$ \\
\hline Age (months) & 0.0528 & 0.0375 & 0.159 & 1.05 & $(0.98,1.13)$ \\
\hline \multicolumn{6}{|l|}{ Vaccination status } \\
\hline Group $0^{\mathrm{a}}$ & 0.0000 & - & - & 1.00 & - \\
\hline Group 1 & -1.4424 & 0.1251 & $<0.001$ & 0.24 & $(0.18,0.30)$ \\
\hline Group 2 & -2.3958 & 0.2264 & $<0.001$ & 0.09 & $(0.06,0.14)$ \\
\hline \multicolumn{6}{|l|}{ Sex of child } \\
\hline Female $^{\mathrm{a}}$ & 0.0000 & - & - & 1.00 & - \\
\hline Male & -0.0996 & 0.1049 & 0.342 & 0.91 & $(0.74,1.11)$ \\
\hline \multicolumn{6}{|l|}{$\begin{array}{l}\text { Mother's age at birth } \\
\text { of child (years) }\end{array}$} \\
\hline $15-19$ & 0.4322 & 0.2058 & 0.036 & 1.54 & $(1.03,2.31)$ \\
\hline $20-24$ & 0.1770 & 0.1736 & 0.308 & 1.19 & $(0.85,1.68)$ \\
\hline $25-29^{\mathrm{a}}$ & 0.0000 & - & - & 1.00 & - \\
\hline $30-34$ & 0.2940 & 0.1727 & 0.089 & 1.34 & $(0.96,1.88)$ \\
\hline $35-39$ & 0.4397 & 0.1741 & 0.012 & 1.55 & $(1.10,2.18)$ \\
\hline $40+$ & 0.4250 & 0.1941 & 0.029 & 1.53 & $(1.05,2.24)$ \\
\hline \multicolumn{6}{|l|}{ Residence } \\
\hline Cell 1 & 0.3255 & 0.1624 & 0.045 & 1.38 & $(1.01,1.90)$ \\
\hline Cell 2 & 0.4850 & 0.1536 & 0.002 & 1.62 & $(1.20,2.19)$ \\
\hline Cell 3 & 0.1132 & 0.1348 & 0.401 & 1.12 & $(0.86,1.46)$ \\
\hline Cell 4a & 0.0000 & - & - & 1.00 & - \\
\hline Cell 5 & -0.2197 & 0.2931 & 0.453 & 0.80 & $(0.45,1.43)$ \\
\hline \multicolumn{6}{|l|}{ Year of birth } \\
\hline $1996^{\mathrm{a}}$ & 0.0000 & - & - & 1.00 & - \\
\hline 1997 & -0.2091 & 0.1416 & 0.140 & 0.81 & $(0.61,1.07)$ \\
\hline 1998 & -0.0726 & 0.1473 & 0.622 & 0.93 & $(0.70,1.24)$ \\
\hline 1999 & 0.2545 & 0.1446 & 0.078 & 1.29 & $(0.97,1.71)$ \\
\hline Constant & -4.9012 & 0.2827 & $<0.001$ & - & - \\
\hline \multicolumn{2}{|l|}{ Number of children } & \multicolumn{4}{|l|}{13,361} \\
\hline \multicolumn{2}{|l|}{ Deaths } & \multicolumn{4}{|l|}{370} \\
\hline \multicolumn{2}{|c|}{ Person-months of observation } & \multicolumn{4}{|l|}{61,045} \\
\hline \multicolumn{2}{|c|}{$-2 \log$ likelihood (d.f.) } & $289.74(16)$ & & & \\
\hline \multicolumn{2}{|l|}{ P-value } & $<0.001$ & & & \\
\hline
\end{tabular}

${ }^{a}$ Reference category.

Note: Group $0=$ No immunizations; Group $1=$ Partial BCG/polio/DPT coverage, no measles vaccine; Group 2 = Full BCG/polio/DPT coverage, no measles vaccine. 
Table 5 Discrete-time hazards regression model for examining the effect of the degree of immunization uptake and mortality in the 9-59-month age group

\begin{tabular}{|c|c|c|c|c|c|}
\hline Variable & Coefficient & Standard error & P-value & Odds ratio & $95 \% \mathrm{CI}$ \\
\hline Age (months) & -0.0574 & 0.0080 & $<0.001$ & 0.94 & $(0.93,0.96)$ \\
\hline \multicolumn{6}{|l|}{ Indicator variables } \\
\hline Ages 9-11 months a & 0.0000 & - & - & 1.00 & - \\
\hline Ages $12-23$ months & 0.3543 & 0.3401 & 0.298 & 1.43 & $(0.73,2.78)$ \\
\hline Ages $24-59$ months & 0.1265 & 0.4151 & 0.761 & 1.13 & $(0.50,2.56)$ \\
\hline \multicolumn{6}{|l|}{ Vaccination status } \\
\hline Group $0^{\mathrm{a}}$ & 0.0000 & - & - & 1.00 & - \\
\hline Group 1 & -1.0910 & 0.1733 & $<0.001$ & 0.34 & $(0.24,0.47)$ \\
\hline Group 2 & -2.1542 & 0.2808 & $<0.001$ & 0.12 & $(0.07,0.20)$ \\
\hline Group 3 & -2.2752 & 0.5841 & $<0.001$ & 0.10 & $(0.03,0.32)$ \\
\hline Group 4 & -2.1108 & 0.2451 & $<0.001$ & 0.12 & $(0.07,0.20)$ \\
\hline \multicolumn{6}{|l|}{ Interaction terms } \\
\hline $\begin{array}{l}\text { Group } 1 \times \\
\quad \text { age } 12-23 \text { months }\end{array}$ & 1.1570 & 0.2141 & $<0.001$ & 3.18 & $(2.09,4.84)$ \\
\hline Group $2 \times$ & & & & & \\
\hline age $12-23$ months & 2.1785 & 0.3169 & $<0.001$ & 8.83 & $(4.75,16.44)$ \\
\hline $\begin{array}{l}\text { Group } 3 \times \\
\quad \text { age } 12-23 \text { months }\end{array}$ & 1.7045 & 0.6240 & 0.006 & 5.50 & $(1.62,18.68)$ \\
\hline $\begin{array}{l}\text { Group } 4 \times \\
\quad \text { age } 12-23 \text { months }\end{array}$ & 1.1019 & 0.2742 & $<0.001$ & 3.01 & $(1.76,5.15)$ \\
\hline $\begin{array}{l}\text { Group } 1 \times \\
\quad \text { age } 24-59 \text { months }\end{array}$ & 0.5705 & 0.2904 & 0.049 & 1.77 & $(1.00,3.13)$ \\
\hline $\begin{array}{l}\text { Group } 2 \times \\
\quad \text { age } 24-59 \text { months }\end{array}$ & 1.0107 & 0.4858 & 0.037 & 2.75 & $(1.06,7.12)$ \\
\hline $\begin{array}{l}\text { Group } 3 \times \\
\quad \text { age } 24-59 \text { months }\end{array}$ & 2.0725 & 0.6436 & 0.001 & 7.94 & $(2.25,28.05)$ \\
\hline $\begin{array}{l}\text { Group } 4 \times \\
\quad \text { age } 24-59 \text { months }\end{array}$ & 1.4496 & 0.2955 & $<0.001$ & 4.26 & $(2.39,7.61)$ \\
\hline Sex of child & & & & & \\
\hline Female $^{\mathrm{a}}$ & 0.0000 & - & - & 1.00 & - \\
\hline Male & 0.1734 & 0.0677 & 0.010 & 1.19 & $(1.04,1.36)$ \\
\hline Residence & & & & & \\
\hline Cell 1 & 0.0810 & 0.1033 & 0.433 & 1.08 & $(0.89,1.33)$ \\
\hline Cell 2 & -0.1391 & 0.1129 & 0.218 & 0.87 & $(0.70,1.09)$ \\
\hline Cell 3 & -0.0428 & 0.0843 & 0.611 & 0.96 & $(0.81,1.13)$ \\
\hline Cell $4^{\mathrm{a}}$ & 0.0000 & - & - & 1.00 & - \\
\hline Cell 5 & -0.6008 & 0.2132 & 0.005 & 0.55 & $(0.36,0.83)$ \\
\hline
\end{tabular}


Table 5 continued

\begin{tabular}{|c|c|c|c|c|c|}
\hline Variable & Coefficient & Standard error & P-value & Odds ratio & $95 \% \mathrm{CI}$ \\
\hline $\begin{array}{l}\text { Number of compound } \\
\text { residents }(\log )\end{array}$ & 0.1482 & 0.0494 & 0.003 & 1.16 & $(1.05,1.28)$ \\
\hline $\begin{array}{l}\text { Mother's age at birth } \\
\text { of child }\end{array}$ & 0.1507 & 0.0448 & 0.001 & 1.16 & $(1.06,1.27)$ \\
\hline Mother resident & & & & & \\
\hline $\begin{array}{l}\mathrm{No}^{\mathrm{a}} \\
\mathrm{Yes}\end{array}$ & $\begin{array}{l}0.0000 \\
0.4979\end{array}$ & $\overline{-} \overline{3114}$ & $\overline{0.110}$ & $\begin{array}{l}1.00 \\
1.65\end{array}$ & $(0.89,3.03)$ \\
\hline Interaction terms & & & & & \\
\hline $\begin{array}{l}\text { Mother resident } \times \\
\text { age } 12-23 \text { months } \\
\text { Mother resident } \times\end{array}$ & -1.1448 & 0.3399 & 0.001 & 0.32 & $(0.16,0.62)$ \\
\hline age $24-59$ months & -0.9637 & 0.3755 & 0.010 & 0.38 & $(0.18,0.80)$ \\
\hline Constant & -5.0837 & 0.3284 & $<0.001$ & - & - \\
\hline \multicolumn{3}{|l|}{ Number of children } & & & \\
\hline Deaths & \multicolumn{2}{|c|}{885} & & & \\
\hline \multicolumn{2}{|c|}{ Person-months of observation } & 42,720 & & & \\
\hline-2 log likelihood (d.f.) & & $727.24(25)$ & & & \\
\hline P-value & & $<0.001$ & & & \\
\hline
\end{tabular}

${ }^{a}$ Reference category.

Note: Group 0 = No immunizations; Group 1 = Partial BCG/polio/DPT coverage, no measles vaccine; Group 2 = Full BCG/polio/DPT coverage, no measles vaccine; Group 3 = Partial BCG/ polio/DPT coverage, measles vaccine; Group 4 = All immunizations (full BCG/polio/DPT coverage, measles vaccine).

and not vaccinated against measles (RR comparing Group 3 to Group $1=1.27,95 \% \mathrm{CI}$ $=[0.73,2.22] ; \mathrm{RR}$ comparing Group 4 to Group $2=1.79,95 \% \mathrm{CI}=[0.83,3.87])$.

\section{Multivariate analysis}

The descriptive statistics presented in the previous section must be interpreted with caution since they cannot account for the fact that children in the various vaccination status categories may have lower mortality risks than unvaccinated children for reasons unrelated to their vaccination status. For example, children who have never been vaccinated may be more likely to live farther away from outreach points or to have 
mothers who are less inclined to use clinical services, both of which would be likely to put them at higher risk of death during childhood independent of their vaccination status. Therefore, multivariate analyses presented below adjust as much as possible for any such inter-group differences.

A discrete-time hazards model considering only the impact of the BCG/polio/ DPT series on mortality was estimated on children between the ages of 4 and 8 months. As above, those who received a measles vaccination prior to age 9 months were censored at the time of vaccination for the purposes of this regression. Also, children who were older than 4 months at the time of the first vaccination survey were not included. The regression results are shown in Table 4.

Children with partial and full BCG/polio/DPT coverage have 76 percent and 91 percent reduced odds of mortality, respectively, relative to unvaccinated children after controlling for age, sex, mother's age, area of residence, and year of birth. These figures are similar to the unadjusted rates presented in the previous section. As described above, other potentially confounding variables were considered and ultimately removed from the final model if they were neither statistically nor programmatically significant.

A second model comparing all five vaccination status groups was estimated on children between the ages of 9 and 59 months. Figure 2 indicated that the relationship between vaccination status and mortality is not constant over this age range. Hence indicator variables for different age ranges and interaction terms are added to allow vaccination impact to be age-dependent.

The regression presented in Table 5 models mortality as a linear function of age and indicates that mortality is decreasing over this age range (odds ratio $[\mathrm{OR}]=0.94$ per additional month of age). Indicator variables for age ranges 12-23 months and 24-59 months are added to the model, leaving ages 9-11 months as the reference category. These variables have the value 1 for the months that the child is in the specified age group and 0 otherwise. The lack of statistical significance of these indicator variables indicates that overall levels of mortality do not differ significantly between these age ranges apart from the general linear decline represented by the first variable.

Given the presence of interaction terms in the model, the coefficients on the vaccination status variables should be interpreted as the relationship between vaccination 
Table 6 Adjusted mortality odds ratios (95\% confidence intervals) by age group and vaccination status

\begin{tabular}{lccc}
\hline & \multicolumn{3}{c}{ Age range (months) } \\
\cline { 2 - 4 } Vaccination status & $\mathbf{9 - 1 1}$ & $\mathbf{1 2 - 2 3}$ & $\mathbf{2 4 - 5 9}$ \\
\hline Group $0^{\mathrm{a}}$ & 1.00 & 1.00 & 1.00 \\
Group 1 & 0.34 & 1.07 & 0.59 \\
& $(0.24,0.47)$ & $(0.83,1.37)$ & $(0.38,0.94)$ \\
Group 2 & 0.12 & 1.02 & 0.32 \\
& $(0.07,0.20)$ & $(0.77,1.37)$ & $(0.15,0.69)$ \\
Group 3 & 0.10 & 0.57 & 0.82 \\
& $(0.03,0.32)$ & $(0.37,0.87)$ & $(0.48,1.39)$ \\
Group 4 & 0.12 & 0.36 & 0.52 \\
& $(0.07,0.20)$ & $(0.29,0.47)$ & $(0.37,0.72)$ \\
\hline
\end{tabular}

${ }^{\text {a }}$ Reference category.

Note: Group 0 = No immunizations; Group 1 = Partial BCG/polio/DPT coverage, no measles vaccine; Group 2 = Full BCG/polio/DPT coverage, no measles vaccine; Group 3 = Partial BCG/polio/DPT coverage, measles vaccine; Group $4=$ All immunizations (full BCG/polio/DPT coverage, measles vaccine).

status and mortality in the 9-11-month age group only (the reference age group). For example, the OR of 0.34 for Group 1 indicates that for children 9-11 months old, those with partial $\mathrm{BCG} /$ polio/DPT coverage have 66 percent lower odds of mortality than unvaccinated children, controlling for other variables.

The coefficients on the interaction terms represent the effect of vaccination status on mortality in that age group relative to the effect in the 9-11-month age group. To see the adjusted effect of vaccination on mortality in the 12-23-month and 24-59-month age groups, we therefore must combine the coefficients on the relevant main effect (e.g., Group 1) and interaction (e.g., Group $1 \times$ age 12-23 months) variables. For example, to understand the relationship of partial BCG/polio/DPT coverage to mortality among 12 23-month-old children, we add the coefficients for Group 1 and for Group $1 \times$ age 12 23 months $=-1.0910+1.1570=0.0660$. Exponentiation yields an OR of $\exp (0.0660)=$ 1.07 , which suggests that there is little difference in mortality between Group 1 and Group 0 in the 12-23-month age group. 
To assist with the interpretation of the interaction terms, Table 6 presents adjusted mortality ORs based on the regression results in Table 5. The table compares Groups 1-4 with Group 0 in age ranges 9-11, 12-23, and 24-59 months after controlling for confounding variables. The adjusted ORs are similar to the crude RRs inferred from Figure 2 and presented in Table 3, suggesting that none of the covariates controlled for in the multivariate analysis significantly confounds the relationship between vaccination status and mortality.

\section{DISCUSSION}

The results of our analysis indicate significant reductions in infant and child mortality associated with receipt of BCG, polio, DPT, and measles vaccinations in KassenaNankana District in northern Ghana. Middle post-neonatal mortality (between the ages of 4 and 8 months) is reduced by three-quarters among children who have received some of the BCG, polio, and DPT vaccinations, and by a remarkable 90 percent for children who have received all of them. Mortality between 9 months and five years is reduced by onethird for those who have received BCG, polio, and DPT vaccinations, and by two-thirds for those who have received the full EPI immunization package (BCG, polio, DPT, and measles). The incremental reduction in mortality associated with measles vaccination among children with full BCG, polio, and DPT coverage is approximately 50 percent. These estimates are unchanged after controlling for potentially confounding background factors.

Our estimate of the all-cause mortality reduction produced by measles vaccination is consistent with a number of studies from a variety of developing-world settings (Kristensen, Aaby, and Jensen 2000; Aaby 1995; Koenig et al. 1991). These studies have consistently shown that measles vaccination campaigns reduce all-cause mortality far in excess of the proportion of child deaths that can be directly or even indirectly attributed to measles, prompting speculation that the vaccine may provide nonspecific protective or immunostimulant benefits. Verbal autopsy data in Navrongo indicate that a mere 3-4 percent of child deaths can be attributed to measles (Binka et al. 1995), and anecdotal evidence suggests that measles incidence is relatively uncommon now that immunization campaigns are inducing high levels of herd immunity. 
Very little research has been published on the effect of the BCG, polio, and DPT vaccines on all-cause morbidity and mortality. Our results are consistent with a study in Greifswald, Germany, that randomly allocated children to receive DPT, polio, and hepatitis B vaccinations on the first or the thirtieth day of their third month of life. German guidelines recommend that children receive these vaccinations during their third month, so both groups were vaccinated as recommended, yet the study design nevertheless permitted a comparison of morbidity between comparable vaccinated and unvaccinated children during the third month of life. The study found markedly lower all-cause morbidity during the third month among those vaccinated at the beginning of the month compared to those vaccinated at the end (Otto et al. 2000). Our findings are partially at odds with data recently published by Kristensen, Aaby, and Jensen (2000) from Guinea-Bissau. In their study, the researchers determined the vaccination status of children 0-6 months of age and assessed mortality six months later. Children vaccinated against BCG had approximately 50 percent lower mortality than those who had not been vaccinated at the initial visit. However, those who had received one DPT shot had nearly twice the mortality of those who had not, after controlling for BCG vaccination status. The mortality of those who had received two or three DPT shots did not differ significantly from the mortality of the unvaccinated.

This paper does not estimate the effects of BCG, polio, and DPT separately because of the high correlation between these vaccinations in this study population. DPT and polio are nearly always administered together, making it practically impossible to differentiate between their effects. It is extremely rare in Kassena-Nankana District for a child to be vaccinated against DPT without first having received a BCG shot. Similarly, very few children in our sample received a BCG shot but were not subsequently vaccinated against DPT. Only 3 percent of those who received a BCG shot did not receive a DPT vaccination by the age of 12 months. However, despite our inability to differentiate between the vaccinations, the dramatic reduction in mortality associated with partial or complete BCG/polio/DPT coverage in this population is clearly not consistent with a deleterious effect of DPT offsetting a beneficial effect of BCG.

Our analysis indicates that even children who receive only part of the EPI package of immunizations benefit from substantially reduced mortality. While Figure $3 \mathrm{~b}$ and 
Table 3 show a clear positive trend linking probability of survival with number of vaccinations received, even children with only partial BCG/polio/DPT coverage have 25 percent lower mortality than the unvaccinated between the ages of 9 and 59 months, and nearly 50 percent lower mortality between the ages of 4 and 59 months. These results suggest that receipt of only part of the EPI package can substantially improve children's chances of survival.

Challenges to internal validity are unavoidable in analyses of the all-cause mortality impact of EPI antigens. It would be unethical to conduct randomized controlled trials of vaccines known to be efficacious in preventing the targeted diseases, apart from designs such as that used in the study by Otto and colleagues (2000), which can only examine a narrow window of age in order to satisfy ethical criteria. Vaccinated children are likely not to be a random sample of all children but rather a select group that differs from those not vaccinated in many important respects that might also be expected to influence their mortality risks. While we used multivariate methods to control as much as possible for differences between vaccinated and unvaccinated children, there are likely to be residual unmeasured differences between the two groups that may be producing these associations. Possible confounding characteristics include parental preference for the health of their children, the genetically determined hardiness and health status of the child, and parental attitudes toward modern health services and health-seeking behavior.

Most of these confounders are difficult to measure in any setting. One confounder that was considered in this analysis is health-seeking behavior. A 1999 panel survey among approximately 6,000 women of reproductive age in Kassena-Nankana District included a module on recent child morbidity and related health-seeking behavior. Approximately 10 percent of the children in this analysis both had mothers interviewed in the panel survey and had an episode of illness reported in the panel. An indicator variable was constructed from the responses to this survey to denote whether the mother sought modern medical treatment for the child during the illness in question, as opposed to seeking traditional treatment or no treatment at all. When the analysis was restricted to the subsample for whom the health-seeking behavior variable was defined and this 
variable was included in the discrete-time hazards model, the mortality impact of vaccination status was unchanged. A subsequent analysis indicated that, excluding the healthseeking behavior variable, the regression produced results in the 10 percent subsample that were similar to those in the full sample.

A further point of caution must be added with respect to the analyses on the 4-8month age group. From Table 1 it is clear that in this age group, the sample used for our analysis is not representative of all children in Kassena-Nankana District but is heavily biased toward children more likely to survive. The implications of this bias for the estimate of the relationship between immunization and mortality is unknown. However, if the reduction in mortality associated with vaccination status is an artifact of the bias in the sample toward surviving children, we would expect the gap in mortality between vaccinated and unvaccinated children to narrow as we move from the fourth to the eighth month of life, since this survival bias decreases in importance at later ages and is absent for children ages 9 months and older. However, Figures $2 \mathrm{a}$ and $2 \mathrm{~b}$ show a fairly constant relationship between vaccination status and mortality risk from the fourth through the eleventh month of life.

The vaccination coverage rates observed for Kassena-Nankana District are much lower than the target of 90 percent set by UNICEF. The rates, which range from 72 percent for BCG to 45 percent for measles, also fall below those recorded at the national level. Since 1988 Ghana has recorded an average of over 80 percent for BCG uptake, for example. The low figures noted for Kassena-Nankana District may be attributed to the high proportion of births delivered at home and the implications for health-seeking behavior. Almost 60 percent of all births in the district occur at home, and these children usually experience the traditional practice of being kept at home until they are more than 8 days old. Thus, the need to send the child for immunization will depend on how the mother perceives the program. Some may see it as an inconvenience rather than a necessity. In some situations traditional practitioners give a long list of taboos to new parents regarding their newborns, including banning the use of needles, with the result that these children are not taken to a health facility for whatever reason because of the fear that they will receive injections. 


\section{CONCLUSION}

The data on child survival and vaccination status in rural northern Ghana give strong support to the argument that efforts to implement the Expanded Programme on Immunization can substantially enhance child survival in high-mortality settings, reducing mortality by up to two-thirds in children who receive the full package relative to children who have received no vaccinations. Others have argued that such vaccination programs will eliminate only the proportion of mortality directly attributable to the targeted diseases (Foster 1995) or that they will have no net effect on all-cause mortality because weak children saved from vaccine-preventable diseases will die of other causes in health-deprived settings (Mosley and Chen 1984). Our data add to a growing body of evidence that suggests that measles vaccination programs, in particular, reduce all-cause mortality substantially beyond the proportion of deaths caused by measles. Our results also indicate that BCG, polio, and DPT vaccinations substantially reduce under-5 mortality; this is at odds with recent findings from Guinea-Bissau and indicates a need for further research on the all-cause mortality impact associated with these vaccines in developing countries. Even children who have received only BCG and one or two shots of DPT and polio vaccines enjoy substantially lower mortality than unvaccinated children. In a high-mortality, sub-Saharan African setting with poor infrastructure such as KassenaNankana District, success in delivering even part of the EPI package can yield substantial health dividends.

\section{References}

Aaby, P. 1995. "Assumptions and contradictions in measles and measles immunization research: Is measles good for something?" Social Science \& Medicine 41(5): 673-686.

Binka, F.N., G.H. Maude, M. Gyapong, D.A. Ross, and P.G. Smith. 1995. "Risk factors for child mortality in northern Ghana: A case-control study," International Journal of Epidemiology 24(1): 127-135.

Binka, F.N., A. Nazzar, and J.F. Phillips. 1995. "The Navrongo Community Health and Family Planning Project," Studies in Family Planning 26(3): 121-139. 
Foster, S.O. 1995. "Potential health impact of immunization," in H. Rashad, R. Gray, and T. Boerma (eds.), Evaluation of the Impact of Health Interventions. Liège: International Union for the Scientific Study of Population, pp. 47-74.

Ghana Statistical Service and Macro International. 1999. Ghana Demographic and Health Survey 1998. Calverton, MD: Ghana Statistical Service and Macro International.

Kasongo Project Team. 1981. "Influence of measles vaccination on survival pattern of 7-35-month-old children in Kasongo, Zaire," Lancet 1(8223): 764-767.

Kelsey, J.L., A.S. Whittemore, A.S. Evans, and W.D. Thompson. 1996. Methods in Observational Epidemiology. New York: Oxford University Press.

Koenig, M.A., V. Fauveau, and B. Wojtyniak. 1991. "Mortality reductions from health interventions: The case of immunization in Bangladesh," Population and Development Review 17(1): 87-104.

Koenig, M.A., M.A. Khan, B. Wojtyniak, J.D. Clemens, J. Chakraborty, V. Fauveau, J.F. Phillips, J. Akbar, and U.S. Barua. 1991. "Impact of measles vaccination on childhood mortality in rural Bangladesh," Bulletin of the World Health Organization 68(4): 441-447.

Kristensen I., P. Aaby, and H. Jensen. 2000. "Routine vaccinations and child survival: Follow up study in Guinea-Bissau, West Africa," British Medical Journal 321(7274): 1435-1438.

Mosley, W.H. and L.C. Chen. 1984. "An analytical framework for the study of child survival in developing countries," in W.H. Mosley and L.C. Chen (eds.), Child Survival: Strategies for Research (supplement to Population and Development Review, vol. 10), pp. 25-45.

Otto, S., B. Mahner, I. Kadow, J.F. Beck, and S.K. Wiersbitsky. 2000. "General nonspecific morbidity is reduced after vaccination within the third month of lifeThe Greifswald study," Journal of Infection 41(2): 172-175.

UNICEF. 1993. The State of the World's Children. New York: United Nations. 


\title{
POLICY RESEARCH DIVISION WORKING PAPERS
}

\author{
Recent Back Issues
}

1999

*120 John Bongaarts, "The fertility impact of changes in the timing of childbearing in the developing world."

*121 James F. Phillips, Wendy L. Greene, and Elizabeth F. Jackson, "Lessons from community-based distribution of family planning in Africa."

122 Mark R. Montgomery, "Mortality decline and the demographic response: Toward a new agenda."

*123 Mark R. Montgomery, Mary Arends-Kuenning, and Cem Mete, "The quantity-quality transition in Asia."

124 Barbara S. Mensch, Wesley H. Clark, Cynthia B. Lloyd, and Annabel S. Erulkar, "Premarital sex and school dropout in Kenya: Can schools make a difference?"

125 John Bongaarts and Rodolfo A. Bulatao, "Completing the demographic transition."

126 Geoffrey McNicoll, "Population weights in the international order."
127 Cynthia B. Lloyd, Carol E. Kaufman, and Paul Hewett, "The spread of primary schooling in subSaharan Africa: Implications for fertility change."

128 John B. Casterline, "The onset and pace of fertility transition: National patterns in the second half of the twentieth century."

129 Mark R. Montgomery, Michele Gragnolati, Kathleen Burke, and Edmundo Paredes, "Measuring living standards with proxy variables."

130 Bamikale Feyisetan and John B. Casterline, "Fertility preferences and contraceptive change in developing countries."

131 Martin Brockerhoff, "Urban growth in developing countries: A review of projections and predictions."

132 Omaima El-Gibaly, Barbara Ibrahim, Barbara S. Mensch, and Wesley H. Clark, "The decline of female circumcision in Egypt: Evidence and interpretation."

* No longer available 
133 Mary Arends-Kuenning and Sajeda Amin, "The effects of schooling incentive programs on household resource allocation in Bangladesh."

134 John Bongaarts and Charles F. Westoff, "The potential role of contraception in reducing abortion."

135 John B. Casterline and Steven W. Sinding, "Unmet need for family planning in developing countries and implications for population policy."

*136 Carol E. Kaufman, Thea de Wet, and Jonathan Stadler, "Adolescent pregnancy and parenthood in South Africa."

137 Valerie L. Durrant and Zeba A. Sathar, "Greater investments in children through women's empowerment: A key to demographic change in Pakistan?"

138 Sajeda Amin, Alaka Malwade Basu, and Rob Stephenson, "Spatial variation in contraceptive use in Bangladesh: Looking beyond the borders."
139 Geoffrey McNicoll, "Managing population-environment systems: Problems of institutional design."

140 Barbara S. Mensch, Barbara L. Ibrahim, Susan M. Lee, and Omaima ElGibaly, "Socialization to gender roles and marriage among Egyptian adolescents."

141 John Bongaarts and Elof Johansson, "Future trends in contraception in the developing world: Prevalence and method mix."

142 Alaka Malwade Basu and Sajeda Amin, "Some preconditions for fertility decline in Bengal: History, language identity, and an openness to innovations."

143 Zeba Sathar, Cynthia B. Lloyd, Cem Mete, and Minhaj ul Haque, "Schooling opportunities for girls as a stimulus for fertility change in rural Pakistan."

2001

144 John Bongaarts, "Household size and composition in the developing world."

145 John B. Casterline, Zeba A. Sathar, and Minhaj ul Haque, "Obstacles to contraceptive use in Pakistan: A study in Punjab."
146 Zachary Zimmer, Albert I. Hermalin, and Hui-Sheng Lin, "Whose education counts? The impact of grown children's education on the physical functioning of their parents in Taiwan."

147 Philomena Nyarko, Brian Pence, and Cornelius Debpuur, "Immunization status and child survival in rural Ghana."

\footnotetext{
* No longer available
} 